Research Article

\title{
Performance Evaluation of CFRP Strengthened Corrosion-Proof Columns
}

\author{
Mohammadamin Mirdarsoltany ${ }^{(D}$, Alireza Rahai ${ }^{(D)}$, and Mohammad Zaman Kabir \\ Department of Civil Engineering, Faculty of Civil Engineering, Amirkabir University of Technology, Tehran, Iran \\ Correspondence should be addressed to Mohammadamin Mirdarsoltany; amin.st@aut.ac.ir
}

Received 28 April 2021; Revised 25 May 2021; Accepted 23 June 2021; Published 10 July 2021

Academic Editor: S. Mahdi S. Kolbadi

Copyright ( 92021 Mohammadamin Mirdarsoltany et al. This is an open access article distributed under the Creative Commons Attribution License, which permits unrestricted use, distribution, and reproduction in any medium, provided the original work is properly cited.

\begin{abstract}
The application of FRP composites in recent years has attracted much attention. Lightweight, high strength, and corrosion resistance are among the properties that make this material available in various forms in construction engineering. The present study analyzed the performance of carbon fiber-reinforced accelerated corrosion-proof box. Nine columns without corrosion and cross-corrosion reinforcement were tested in laboratory and software. Syntax reinforcement was applied locally to the damaged area with respect to a transverse and longitudinal layer. The results of the axial test showed that, due to corrosion, the damaged site was weakened by the loading and severe resistance decreased, and the range of damage points due to the axial load was highly deformed compared to the initial state. The damage caused on both sides of the steel column had a significant effect on reducing the hardness and deformation of the steel columns; it is worth noting that the corrosion on both sides of the steel column had the most variations among the samples. Application of CFRP with 2 layers in the damaged steel columns resulted in increased bearing capacity and hardness in the affected area due to corrosion so that reinforcement of these columns by carbon fibers improved the axial strength.
\end{abstract}

\section{Introduction}

Today, due to the expansion and importance of oil and maritime transport activities and attention to mining in the seabed, construction activities such as the construction of piers, platforms, and similar structures in coastal and oceanic areas have increased significantly. Although concrete is considered a durable material in the sea environment, many breakdowns of concrete structures along the coast have been reported. When designing concrete and metal structures that are located in the vicinity of seawater, it is necessary to consider the effect of destructive environmental factors to which concrete is exposed during the long years of operation and it seems that the designs based on the criterion of strength for such structures are not enough. In addition to the strength criterion, the durability of concrete in these areas should also be considered.

FRP composites are relatively new materials that are not widely used [1]. Today, high-rise buildings are constructed with steel and concrete structures, and each of the concrete and steel structural systems has its advantages and disadvantages, which cannot be expressed in this article, and employers, according to their needs, one of the two. They choose the type of structural system. However, what is less considered when choosing the structural system of buildings is their ability to resist accelerated corrosion. In this study, the focus is on accelerated corrosion in incomplete steel structures. In general, steel structures, with advantages of high strength and good ductility, also have disadvantages that have limited their use in some structures. Steel can be considered vulnerable in two ways, including its vulnerability to heat and corrosive environmental factors. Accelerated corrosion is one of the deadliest hazards that structures may face during their lifetime [2].

In recent years, attention has been paid to the reinforcement of damaged structures, seismic improvement, and increasing the flexural capacity of steel members. Moreover, to improve and modify traditional methods, new 
reinforcement methods have been replaced in order to facilitate reinforcement and increase the capacity of structures, making structural engineers use polymer systems reinforced with polymer reinforcing fibers. Most research has been done on reinforcing steel structures with FRP. Reinforcement of steel members with less axial load has been studied. Therefore, in this research, the compressive load capacity of a short steel column reinforced with FRP has been investigated. The use of FRP can be used not only to restore the lost strength of the steel section due to corrosion but also to increase the bearing capacity of healthy sections, increase the fatigue life, and prevent the growth of cracks, provided that conditions such as adhesion resistance are met [3].

Contrary to popular belief, the parameters of load and strength in the design of structural members are not definite quantities and are random variables, so it is impossible to design completely safe structures and using a probabilistic approach to calculate the performance of structural members in design is inevitable. In building corrosion safety regulations, there is always a classification in terms of building use, and the level of requirements in each group of buildings varies depending on their importance. Once the level of corrosion safety expectations for a building is determined, the designer must use materials with good properties and behavior against accelerated corrosion. Therefore, it is necessary for building designers and engineers to provide a classification (or classifications) of the behavior and characteristics of materials and materials against corrosion [4].

\section{Literature Review}

Kitada et al. investigated the behavior of a circular steel column filled with ordinary concrete and recycled concrete reinforced with CFRP. Carbon fiber-reinforced circular columns were studied in the laboratory. The use of CFRP increases the ductility and bearing capacity, and increasing the number of layers increases the bearing capacity, and to increase the strength of steel columns, FRP and concrete jacket methods can be used. This study showed that the use of CFRP materials for reinforcement increases the compressive capacity and loading and the use of these materials in a semitorsional manner has less axial compressive strain than a complete torsion [5].

Harries et al. worked on reinforcing steel columns filled with concrete by CFRP; they tested a number of sections of steel filled with mortar and reinforced with FRP. For 22 samples, they examined the performance such as reinforcement method, concrete type, and cross-sectional shape and concluded that CFRP screw circumference on solid and hollow circular columns has a better effect than squareshaped sections after reinforcement of middle failure [6]. This article presents a reinforcement method to improve the vibration resistance of steel in compression, while a FRP tube filled with mortar is rolled out of the steel member and wrapped in FRP fabric at the end of the tube. Through axial compression tests in 18 specimens with two-way symmetrical cross-section, load-strain expansion and failure modes were obtained and the bearing capacity and flexibility were increased. The cross-sectional effects of the steel layers reinforced with the FRP layer wrapped at the end of the samples were investigated. It was found that after reinforcement, the failure modes of midheight steel produced from the steel member changed to local damage at the end of the steel due to global bending. As a result, load-bearing capacity increased by 44 to 215 percent. A segmentation model was developed for the reinforced specimens, with a calculated load-bearing capacity consistent with the test results [7].

Bambak et al. examined the periodic performance of circles and squares, so-called double-walled hollow columns, and placed the columns under a fixed load and a reverse bending load. Column failure was characterized by longitudinal carbon fiber rupture following peripheral fiber rupture. The test results showed that increasing the axial load level of the columns increases the flexural ductility, while increasing the carbon fiber layers in the outer tube increases the strength but decreases the flexural ductility of the column. The mechanical model in this article is completed for HSS split columns. The integrated theory is as follows: this introduces a confidential factor to describe the performance of a composite steel pipe and aerated concrete. The predicted load to deformation ratio was in good agreement with the test results. The theoretical model is used to investigate the effect of important parameters that determine the final strength of composite columns. Parametric and experimental studies provide information for the development of formulas for calculating the ultimate strength and axial load relative to the axial pressure curves of composite columns [8].

Jama and Bambak conducted a laboratory study of stress-strain behavior, final bearing capacity, and fracture modes of steel section filled with concrete and reinforced with CFRP fibers transversely. They wrapped the carbon fibers in strips around the column, taking into account factors such as the thickness and distance of the strips. As the distance between the CFRP strips increases, buckling occurs in the fiber-free part, and the greater the number of layers, the better the control of axial deformation. Proper spacing between CFRP strips is essential to delay buckling and increase ultimate bearing capacity and axial strain stress behavior. CFST concrete pipe members are very popular in the construction industry, and at the same time, structural aging and member failure are often reported. Measures such as the implementation of new materials and reinforcement techniques are necessary to deal with this problem. This research aims to investigate the structural progress of CFST sections with ordinary external concrete bonded with fiber-reinforced polymer (FRP) composites. For this study, mildly pressed mild steel pipes with the main variable having FRP properties are used. Carbon fiber-reinforced polymer fabrics (CFRP) are used as horizontal strips (lateral relations) with several other parameters such as the number of layers and width and spacing of strips. Among the 30 specimens, twenty-seven were grafted outside the $50 \mathrm{~mm}$ wide strip of CFRP tapes at intervals of 20,30 , and $40 \mathrm{~mm}$, and the remaining three specimens were unbounded. Experiments were performed before column failure to fully understand 
the impact of FRP parameters on the compressive behavior of square CFST sections, including their failure mode, axial stress pressure behavior, and load-carrying capacity. From the test results, it was found that the external connection of CFRP strips effectively causes external thrust pressure, accelerates the local delay of the steel pipe, and also increases the load-carrying capacity. Finally, an analytical model is proposed to predict the axial load capacity of reinforced CFST sections under compression [9].

Haedir et al. analyzed the behavior of a concrete steel bridge reinforced with CFRP sheets; the connection was made to the bottom and the beams. The test results showed that the strength and stiffness of the steel-concrete composite bridge increased up to $45 \%$ compared to the main strength of the beam. The use of advanced composite materials to rehabilitate declining infrastructure is accepted worldwide. Conventional techniques for reinforcing unsuitable bridges are costly, time-consuming, and labor-intensive. Many new techniques use lightweight, high strength, and corrosion resistance polymers reinforced with FRP laminate for repairs and application completion. The loadcarrying capacity of a composite steel box is significantly wrapped with carbon fiber-reinforced polymers laminate to its tension flange. In this article, the results of a study on the behavior of reinforced concrete steel composite columns with CFRP sheets under static loading are presented. A total of three large composite columns made of steel sheet with a thickness of $75 \mathrm{~mm}$ have been prepared and tested with $910 \mathrm{~mm}$ concrete. Constant CFRP leaf thickness and a number of other layers 1,3 , and 5 were used in the samples. The test results showed that the CFRP epoxy bond sheet increased the final bearing capacity of steel composite channels and the behavior can be predicted by traditional methods [10].

By examining the failure of thin-walled steel columns at the pier, Kalavakunta et al. determined that most of the failures were of the local buckling type, which reduced the load-bearing capacity and increased the deformation. This article describes (1) some computer programs for the analysis of fixed plastic/dynamic elastoplastic displacement used in the design of steel bridges; (2) final strength and design methods for steel sheets, sheets, and columns made of compression-resistant steel; (3) seismic design and completion methods for new and existing postearthquake Hyogo-Ken Nambu bridges; (4) friction-type joints and tension-type joints with strong bolts and nuts and development of high-performance fins in Japan. These are the topics that the authors discuss: the new technologies of steel bridges under development in Japan are as follows: the development of high-performance steel, new fiber materials, new types of bridges, performance-based design methods, seismic design methods against Level 2 earthquakes like the Hyogo-Ken Nambu earthquake, and the bridge management system [11].

Hadianfard et al. showed that the use of CFRP to reinforce short canned steel sections under axial impact showed that the use of these materials increases energy absorption and strength. Moreover, studies on steel sections showed failure energy and cross-section strength. Steel-short boxes depend on the type of steel and the ratio of CFRP thickness to CFRP width. The use of CFRP increases the ultimate bearing capacity and specific energy; the reinforcement of CFRP structures has increased, traditionally in use with concrete structures, and more recently in applications with steel structures. This article presents experiments and analyzes of the mechanism of plastic square hollow square reinforced steel using CFRP external bonding reinforcement by deformation in axis-symmetric collapse mode under large static-like axial compression. The process of forming the empty column delay was such that the flat sides formed the known structure of the roof. The collapse was done gradually by folding around the hinged lines and producing four corners. The expression for the plastic axial load of a falling plastic is obtained by equating the total energy absorbed in the bending and the external work done during the deformation of the composite pipe. It has been shown that the loaded values and loads of the predicted loads are instantaneously well compared with the test results [12].

Liu et al. evaluated the effect of transverse and longitudinal reinforcement with CFRP in ten short columns in the laboratory. This article presents the design and experimental design of CFRP external carbon fiber-reinforced polymer sheets for the reinforcement of short circular tubular columns. In addition to ease of handling due to being lightweight, a high-strength CFRP sheet box is somehow limited for thin steel wall retardation. Ten circular hollow columns composed of cold steel with external CFRP columns (adjacent outer and longitudinal rectangles) were tested under compressive pressure. Laboratory results show that fiber-reinforced steel pipe reinforcement increases the capacity of the axial section. The design variables considered to evaluate the reinforcement efficiency are the strength of the steel performance, the modulus of elasticity of the carrot fiber, and the amount and configuration of the fiber reinforcement. The results indicate the ease of using such a curve in FRP reinforcement or redesign of tubular columns to increase section capacity [13].

Teng et al. studied the CFRP-reinforced edged canal column under axial load. They studied the channel-shaped column in two ways: gluing the fibers to the whole column and gluing to the core in the laboratory and found that the bearing capacity increased up to $16.75 \%$ in the reinforced channel section and up to $10.26 \%$ in the reinforced sample. Due to the layering and separation of CFRP, our capacity reduction and sudden failure were considered and the use of CFRP increased the bearing capacity. It was concluded that surface and temperature preparation are two important factors to achieve proper adhesion between steel and fibers; carbon fiber-reinforced polymer composites (CFRP) are of high performance and potential for use in reinforcement, completion, and reconstruction of parts. In this article, design methods for the axial load capacity of cold steel reinforced steel column reinforced polymer with carbon fiber-reinforced polyester (CFRP) are proposed. For validation purposes, the results are based on a proposed design criterion of North American specifications for the design of steel and euro-shaped steel structures for cold members, and the sheet is compared with experimental test data. The test 
results showed that the capacity of the columns is close to the theoretical values predicted by the regulations. Some of the samples tested had reduced capacity and premature failure due to peeling and depletion of CFRP from steel. Various experimental studies have been proposed to carry out future work to validate and update the design equations. From experimental studies, it has been seen that there is a significant increase in strength due to the enhancement of CFRP $[14,15]$. Tanabandeh and Gardoni used probabilistic capacity models for estimating the fragility of structural components [16].

\section{Materials and Methods}

In order to investigate corrosion or structural defects on the capacity of steel columns, a number of laboratory samples are first made and placed under axial load. The results of these experiments, including the displacement curve of the column tip and the axial force created in the column, will be quantitatively evaluated along with the shape and mode of failure of the members. The results of this study, including the material and its mechanical properties, support conditions, and loading methods, will be used to simulate the finite elements of the samples and calibrate the parameters used. After extracting the simulation results and validating them with the values obtained from the laboratory, the calibrated parameters are used to make more samples with more diverse variables. Due to the application of the finite element method along with laboratory studies in the analysis of models used in research, the obtained information will be presented and studied in the form of graphs and tables. In this research, the first samples of incomplete steel columns (9 samples) are designed and after construction, according to the research requirements in the laboratory, they are subjected to accelerated corrosion. Then, according to the results obtained from experimental samples, computer models are simulated and calibrated and the same number of samples will be prepared and studied for parametric study. Therefore, the method used in this research will be the laboratory method along with computer analysis methods (finite element method).

\section{Finite Element Model}

Before any research, to ensure the validity of the software used, we must model an example of past research by the software. For this purpose, the results of a laboratory sample, conducted by Bombach et al. [17] according to Figure 1, have been studied and modeled. In this experiment, a box-shaped member with dimensions of $2 \times 100 \times 100 \mathrm{~mm}$, a height of $300 \mathrm{~mm}$ with a modulus of elasticity of $200 \mathrm{GPa}$, a Poisson coefficient of 0.3 , CFRP fibers with a modulus of elasticity of $230 \mathrm{GPa}$, and final strength of $3790 \mathrm{MPa}$ has been used. According to Figures 2(a) and 2(b), the degree of adaptation of the force-displacement curve in the sample is modeled and compared with the laboratory sample being very accurate, which indicates the correct choice of grid size, application of optimal boundary conditions, and appropriate analysis and modeling. It was a software example. As it is known, for simple and reinforced columns, mesh size with a score of 10.5 is the best case in validation [18]. Moreover, with this mesh score, we were faced with the best answer and the lowest percentage difference compared to the laboratory sample. Table 1 compares the results of steel box member analysis with the number of different FRP layers, the critical load, and the percentage difference of the final load in the sample. In Figures 2(a) and 2(b), F0 means no reinforcement, $F 1$ means coating with one layer of CFRP, and F2 means coating with two layers of CFRP. NU means modeled sample and EX means laboratory sample. All modeled elements were considered solid and modeled using FEM according to Figure 3.

\section{Mechanical Properties}

In this study, the reinforced specimens were reinforced in two layers (longitudinal and transverse) with a twist at the injury site and a $20 \mathrm{~mm}$ overlap (Table 2).

The steel used in this research has a final strength of $336 \mathrm{MPa}$ and a final strain of $12 \%$, which is modeled nonlinearly in the software, with an elasticity of $200 \mathrm{~GB}$ and a Poisson's ratio of 0.3 . In this research, in order to strengthen and improve the performance of the defective box steel column, carbon fibers have been used to achieve the initial performance of the compression member. The method of using carbon fibers was twisted in the defect area. The adhesive used in this study was used to enhance the performance of box columns with CFRP carbon fibers (Tables 3 and 4).

Compression-loaded box steel columns have nine specimens, including one intact specimen, four specimens with (horizontal) defects, and four specimens reinforced with CFRP carbon layers. To name the steel column columns with horizontal defects, a horizontal defect in the center has been applied as follows. The horizontal parameters were $\mathrm{H}$, the lateral $\mathrm{S}$, the middle $\mathrm{M}$, and the defect $\mathrm{D}$.

Dimensions of the defect: the length and width of the defect are equal to $40 * 40 \mathrm{~mm}$, respectively $[20,21]$. Moreover, the number 2 indicates the number of defects; it should be noted that the length of the defect on both sides decreases to $20 \mathrm{~mm}$ on both sides (Table 5). The first word $\mathrm{M}$ indicates a defect in the middle of the surface of the steel column (Middle). Second word S indicates a defect with a side position (Side); third word $\mathrm{H}$ indicates that the defect is horizontal (Horizontal). The fourth word D indicates the word defect (Defect).

FEM provides extensive capabilities for simulation in linear and nonlinear applications. Problems with multiple components and different materials can be simulated by defining the geometry of each component, assigning its constituent materials, and then defining the interaction between these components [22,23]. The present study shows the high capability of FEM that the simulation of the samples provided the ability to examine structures with a suitable graphical environment. The selection of the appropriate element and mesh size and the specifications of the studied materials were expressed in this chapter. Examination of the results of the modeled samples showed defects in the steel 

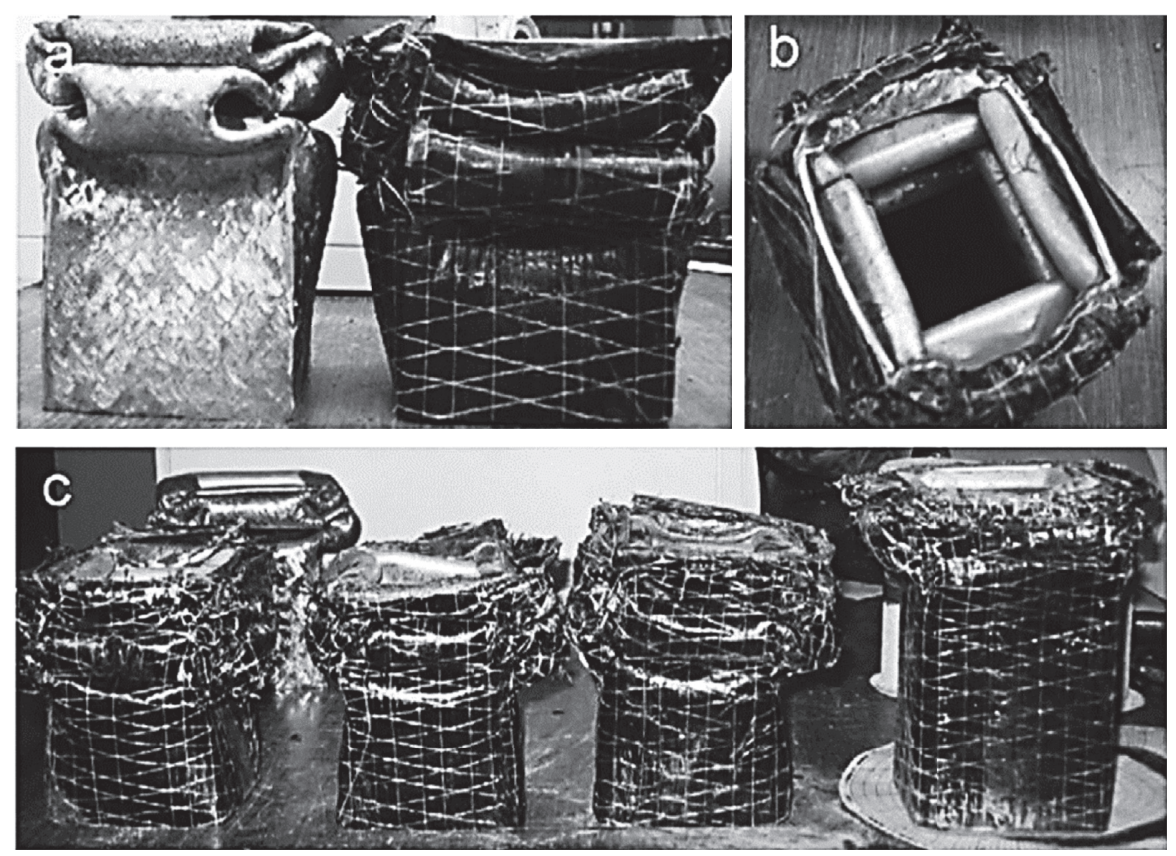

FIGURE 1: Laboratory sample of Bombach et al. [17].

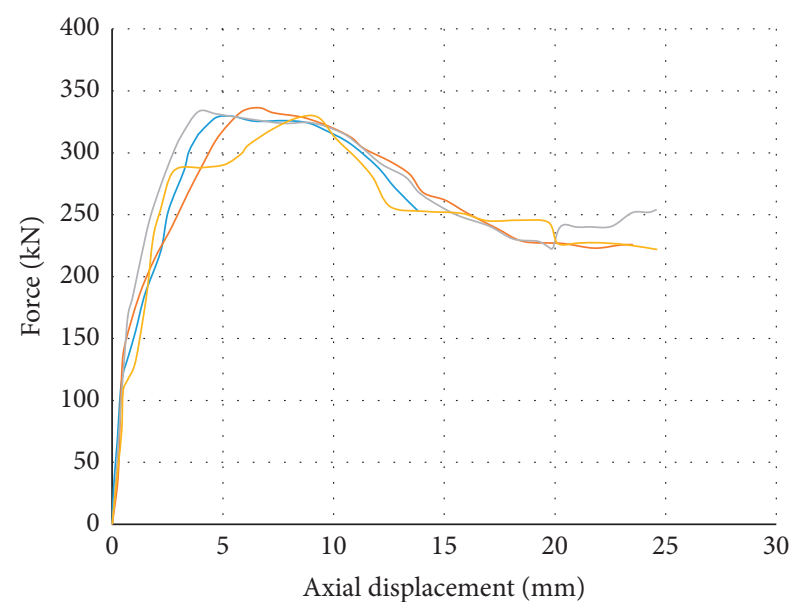

$\begin{array}{ll}- \text { NU (MESH 10.5)-F1 } & - \text { NU (MESH 10)-F1 } \\ \text { EX-F1 } & \text { NU (MESH 9.5)-F1 }\end{array}$

(a)

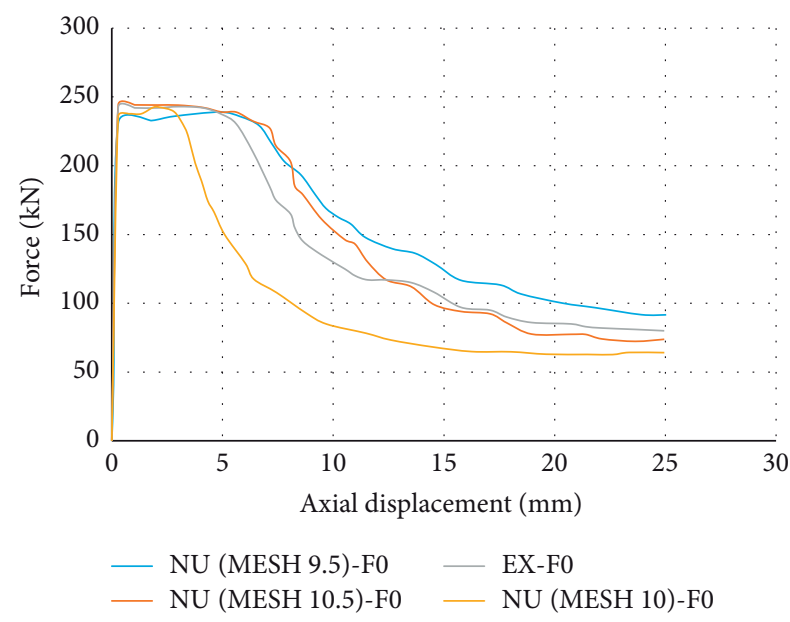

(b)

Figure 2: Validation results of modeling. (a) Retrofitting sample. (b) Nonretrofitting sample [17].

TABLE 1: Comparison of results obtained from laboratory samples and numerical modeling.

\begin{tabular}{lcccccc}
\hline Number & $\begin{array}{c}\text { Cross-section } \\
\text { dimensions }(\mathrm{mm})\end{array}$ & $\begin{array}{c}\text { Height } \\
(\mathrm{mm})\end{array}$ & $\begin{array}{c}\text { Layers of } \\
\text { CFRP }\end{array}$ & $\begin{array}{c}\text { Critical load from the } \\
\text { laboratory }(\mathrm{kN})\end{array}$ & $\begin{array}{c}\text { Critical load from numerical } \\
\text { modeling }(\mathrm{kN})\end{array}$ & $\begin{array}{c}\text { Percentage } \\
\text { error }\end{array}$ \\
\hline 1 & $2^{*} 100^{*} 100$ & 300 & 0 & 238.2 & 239.59 \\
2 & $2^{*} 100^{*} 100$ & 300 & 1 & 338 & 337.1 \\
3 & $2^{*} 100^{*} 100$ & 300 & 2 & 425 & 427.31 \\
\hline
\end{tabular}




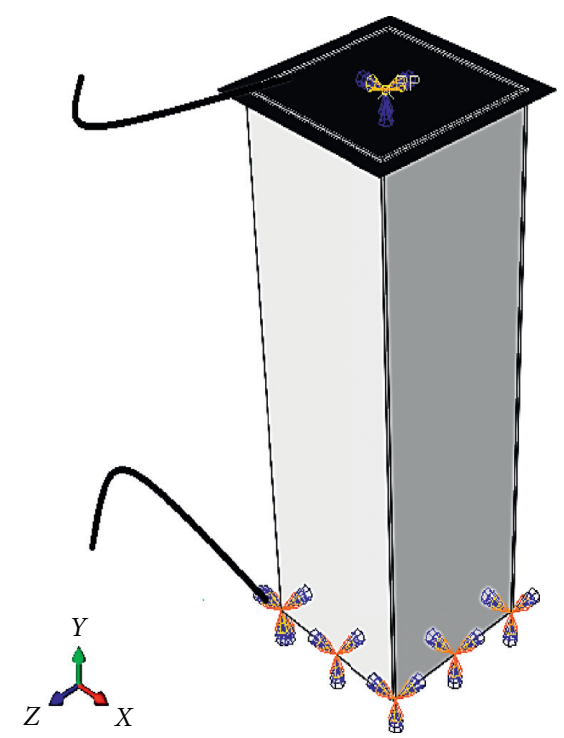

Figure 3: Sample validation modeling of Bombach et al. [17].

columns under axial load, reduced loads, stiffness, and increased deformation in the area of damage. Defects in steel columns will increase the rate of deformation and drop in strength. High-strength CFRP fibers increased the stiffness of the injured limbs, and the placement of the CFRP fibers transversely and longitudinally helped repair the damaged element.

\section{Examination of Laboratory Samples}

6.1. Laboratory Results. In this section, the results of experiments performed on 9 samples are reviewed. Figure 4 shows the force-displacement diagram of the laboratory samples. It can be seen that the control sample has surrendered due to the force of $158 \mathrm{kN}$ and its maximum displacement at the yield point was $8.8 \mathrm{~mm}$ [24].

\subsection{Comparison of Modeling and Laboratory Results.} Figure 3 shows the force-displacement diagram of laboratory and modeled specimens. It can be seen that in Figure 5, in terms of sample MHD2-40*40, the two diagrams are in good agreement with each other. It is also clear from the laboratory diagram that the maximum bearing capacity occurred up to $112 \mathrm{kN}$. We were in the plastic range and the maximum displacement continued up to $4.9 \mathrm{~mm} \mathrm{[25].}$

Figure 6 shows that in the SHD2-40*40 sample, the two diagrams fit well together. It is also clear from the laboratory diagram that the maximum bearing capacity occurred up to $95 \mathrm{kN}$. Then, we saw the displacement behavior in the plastic range and the maximum displacement continued up to $7.5 \mathrm{~mm}[26]$.

It can be seen that in Figure 4 and in the SHD $40 * 40$ sample, up to a force of $128 \mathrm{kN}$, the two diagrams are in good agreement with each other. Then, we saw the displacement behavior in the plastic range and the maximum displacement continued up to $6.5 \mathrm{~mm}$.

It can be seen that in Figure 7 and in the sample MSHD2-40*40, the two diagrams were in good agreement with each other. It is also clear from the laboratory diagram that the maximum load capacity occurred up to $107 \mathrm{kN}$. The displacement behavior was in the plastic range and the maximum displacement continued up to $6.9 \mathrm{~mm}$. In Figure 8 and in the sample MHD2-40 40 $-1 \mathrm{~T} 1 \mathrm{~L}$, the two diagrams are in good agreement with each other [28, 29].

It can be seen that, in Figure 9 and in the sample SHD2$4 * 40-1 \mathrm{~T} 1 \mathrm{~L}$, the two diagrams are in good agreement with each other. It is also clear from the laboratory diagram that the maximum load capacity occurred up to $129 \mathrm{kN}$. We saw the displacement behavior in the plastic range and the maximum displacement continued up to $6.8 \mathrm{~mm}$. It can be seen that in Figure 10 and in the SHD40*40-1T1L sample, the two diagrams fit well with each other. The maximum carrying capacity occurred up to $140 \mathrm{kN}$. On the other hand, this sample witnessed the displacement behavior in the plastic range, and the maximum displacement continued up to $8.2 \mathrm{~mm}$ [30].

In Figure 11, it can be seen that in the sample MSHD2$40 * 40-1 \mathrm{~T} 1 \mathrm{~L}$, the two diagrams are in good agreement with each other. It is also clear from the laboratory diagram that the maximum load capacity occurred up to the limit of $125 \mathrm{kN}$. The displacement behavior was in the plastic range and the maximum displacement continued up to $11.1 \mathrm{~mm}$.

It can be seen that in Figure 12 and in the control sample, the two diagrams are in good agreement with each other. It is also clear from the laboratory diagram that the maximum load capacity occurred up to $158 \mathrm{kN}$. This was in the plastic range and the maximum displacement continued up to $8.8 \mathrm{~mm}$ (Table 6).

6.3. Investigation of Rupture Modes. To study the fracture modes of canned steel columns, we first examine the column with horizontal defects. As can be seen from Figure 13, specimens with a horizontal defect created in the steel column wall experienced local buckling during loading. The location of the defects caused by loading underwent axial deformation of the local buckling type, and the damaged areas reduced the axial strength in the samples [32].

As it is clear from the injury sites, the concentration of stress and the reduction of stiffness occurred in the defective areas. The position of the carbon fiber reinforcement proved that these fibers increased the hardness and ductility by completely covering the steel column. According to the samples reinforced with two layers of carbon fibers, it was determined that these fibers, by completely surrounding the damaged area, delayed the rupture around the defect.

Figures 13 and 14 show the final deformations of short steel columns with defects in two walls. Axial failure on these members was investigated until complete failure because the axial load of the column without carbon layer on the side sides suffered local buckling and complete failure. CFRP composites, as suitable materials for strengthening steel columns, played an effective role in improving the compression member so that 
TABLE 2: Dimensions and characteristics of box steel column [17].

\begin{tabular}{lccccccc}
\hline & \multicolumn{3}{c}{ Specifications of box steel column } & & \multicolumn{2}{c}{ Strain (\%) } \\
Length * width & $\begin{array}{c}\text { Thickness } \\
(\mathrm{mm})\end{array}$ & $\begin{array}{c}\text { Height } \\
(\mathrm{mm})\end{array}$ & $\begin{array}{c}\text { Cross-section } \\
(\mathrm{mm})\end{array}$ & $\begin{array}{c}\text { Modulus of elasticity } \\
(\mathrm{GPa})\end{array}$ & $\begin{array}{c}\text { Tensions (MPa) } \\
\text { Cross tension } \\
\text { Fy }\end{array}$ & $\begin{array}{c}\text { Final } \\
\text { tension }\end{array}$ & $\begin{array}{c}\text { Final } \\
\text { strain }\end{array}$ \\
\hline $70 * 70$ & 2 & 300 & 2.7 & 200 & 250 & 336 \\
\hline
\end{tabular}

TABLE 3: CFRP carbon fiber [17].

\begin{tabular}{lcccc}
\hline Thickness $(\mathrm{mm})$ & Density $\left(\mathrm{g} / \mathrm{cm}^{3}\right)$ & Tensile strength $(\mathrm{MPa})$ & Modulus of elasticity $(\mathrm{MPa})$ & Final strain \\
\hline 0.17 & 1.76 & 3790 & 230000 & 1.2 \\
\hline
\end{tabular}

Table 4: Properties of epoxy resin [17].

\begin{tabular}{lcc}
\hline Tensile strength $(\mathrm{MPa})$ & Modulus of elasticity $(\mathrm{MPa})$ & Final strain $(\%)$ \\
\hline 75 & 3 & $3-4.5$ \\
\hline
\end{tabular}

TABLE 5: Bearing capacity of the models modeled in ABAQUS program.

\begin{tabular}{lcc}
\hline Carrying capacity $(\mathrm{kN})$ & Sample name & Number \\
\hline 139 & Control & 1 \\
98 & MHD2-40 $\times 40$ & 2 \\
84 & SHD2-40 $\times 40$ & 3 \\
115 & SHD- $40 \times 40$ & 4 \\
98 & MSHD2-40 $\times 40$ & 5 \\
112 & MHD2-40 $\times 40-1 \mathrm{~T} 1 \mathrm{~L}$ & 6 \\
115 & SHD2-40 $\times 40-1 \mathrm{~T} 1 \mathrm{~L}$ & 7 \\
127 & SHD-40 $\times 40-1 \mathrm{~T} 1 \mathrm{~L}$ & 8 \\
119 & MSHD2-40 $\times 40-1 \mathrm{~T} 1 \mathrm{~L}$ & 9 \\
\hline
\end{tabular}

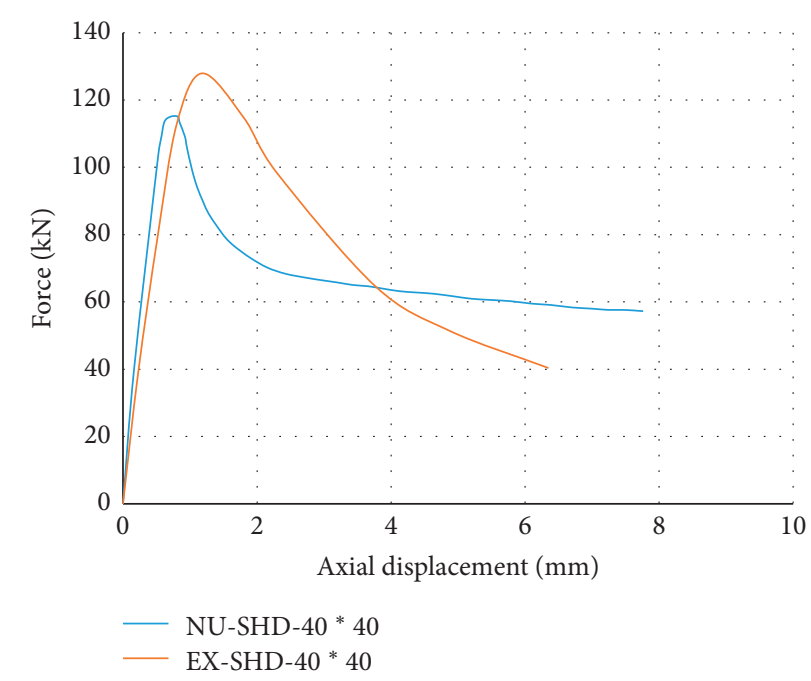

FIgURE 4: Force-displacement diagram of model and laboratory sample [27].

these fibers, by covering the entire length of the column with two transverse and longitudinal layers, increase the stiffness and strength of the samples.. Moreover, the effect of using these fibers has been very effective in controlling buckling. Figures 15 and 16 show the effect of using CFRP fibers.
As investigated, the effect of carbon layers on box steel columns is very good and strengthening these members with two layers of CFRP will help to control axial rupture and increase ductility and energy absorption. Examination of the deformations obtained from the laboratory and its adaptation to 


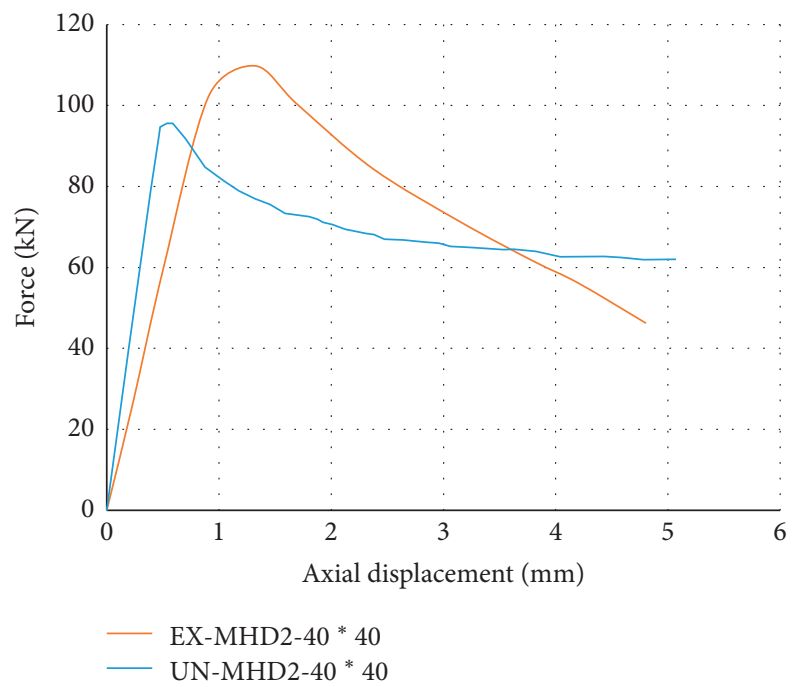

FIgURE 5: Force-displacement diagram of model and laboratory sample.

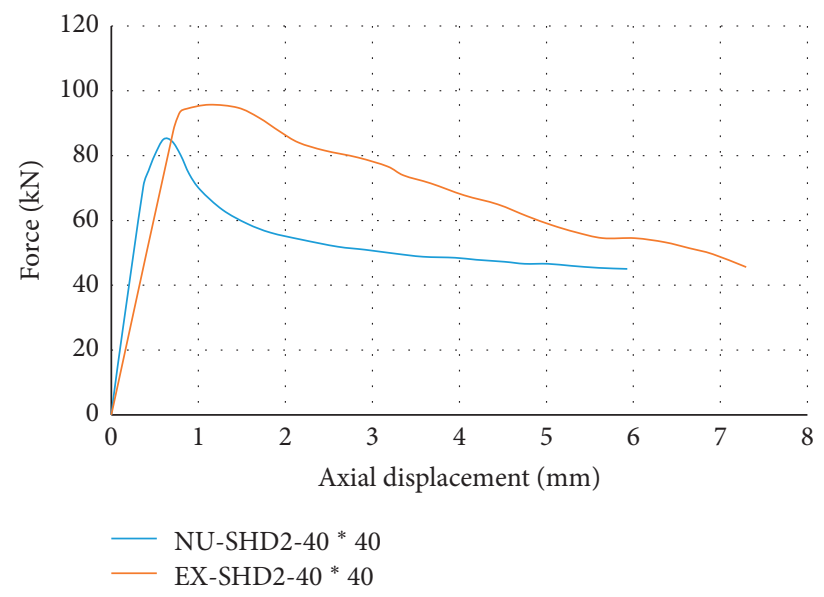

FIgURE 6: Force-displacement diagram of model and laboratory sample.

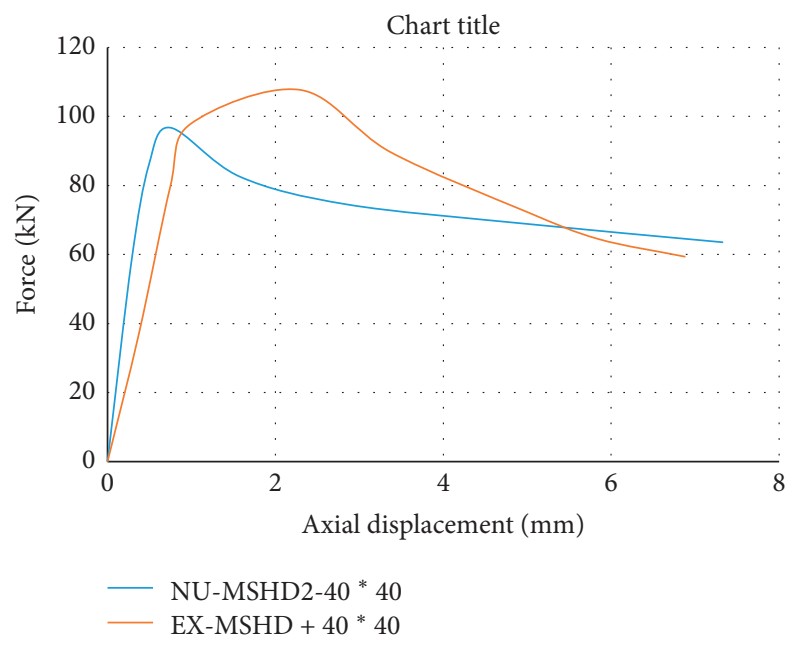

FIGURE 7: Force-displacement diagram of model and laboratory sample [27]. 


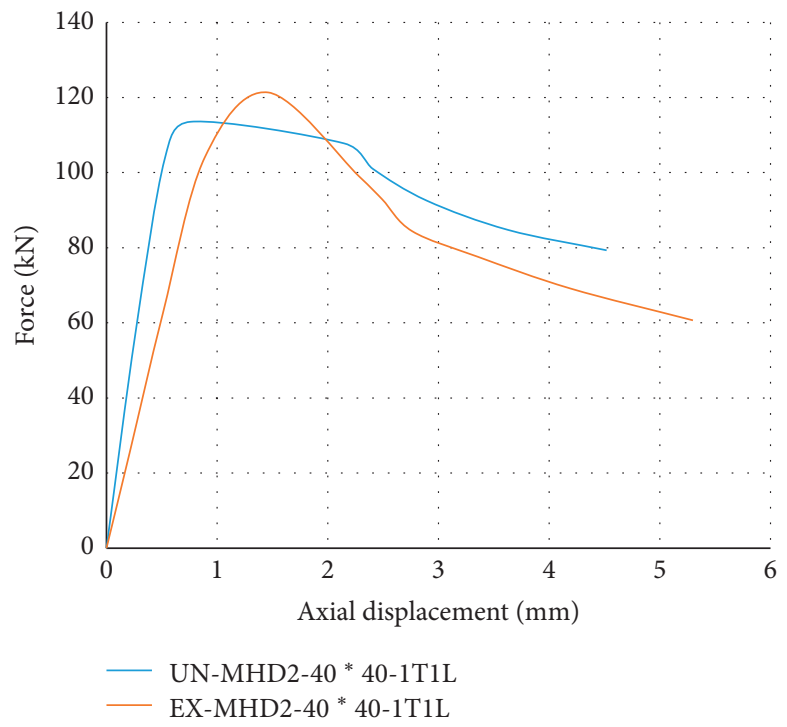

FigURE 8: Force-displacement diagram of model and laboratory sample.

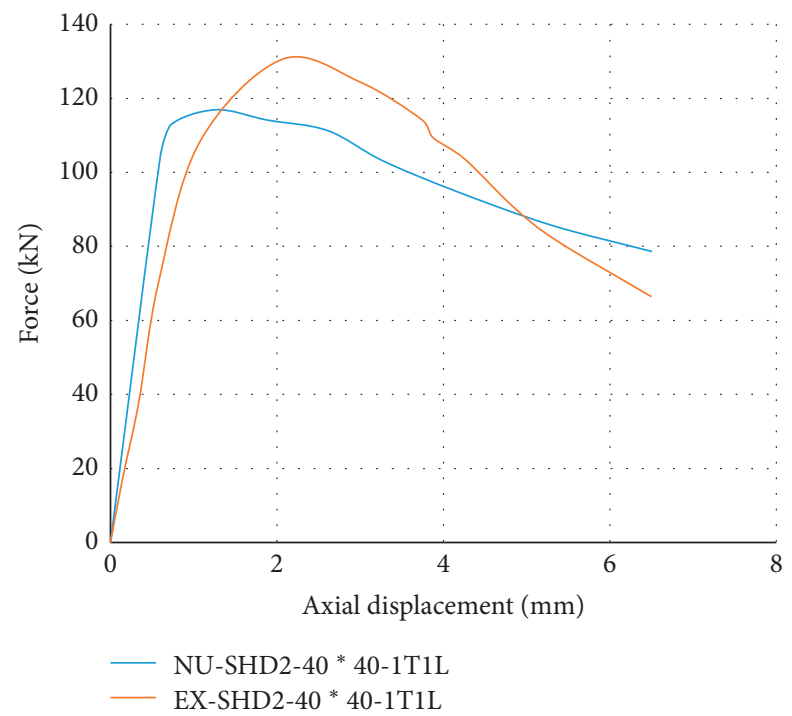

FigURE 9: Force-displacement diagram of a modeled and laboratory sample.

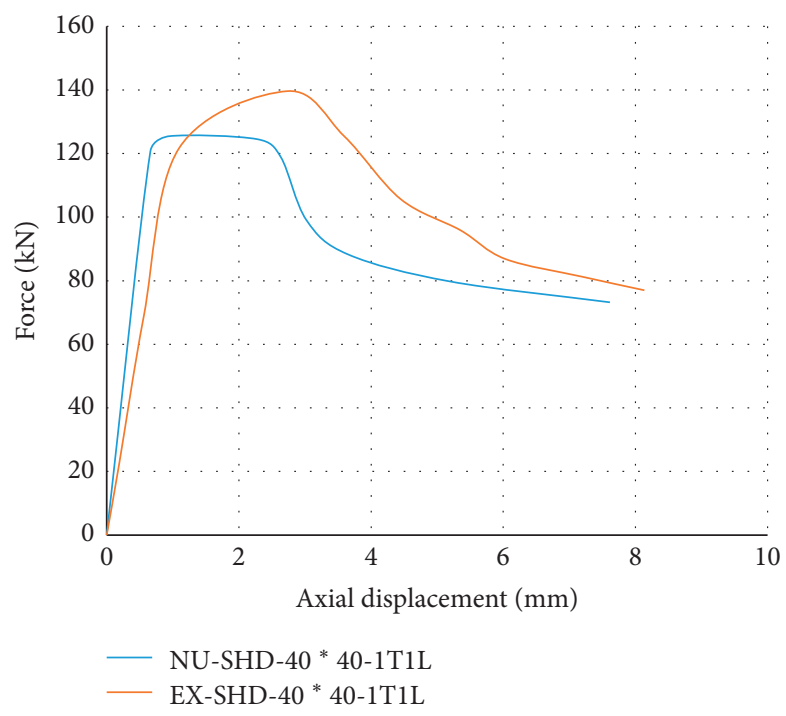

FigURE 10: Force-displacement diagram of model and laboratory sample. 


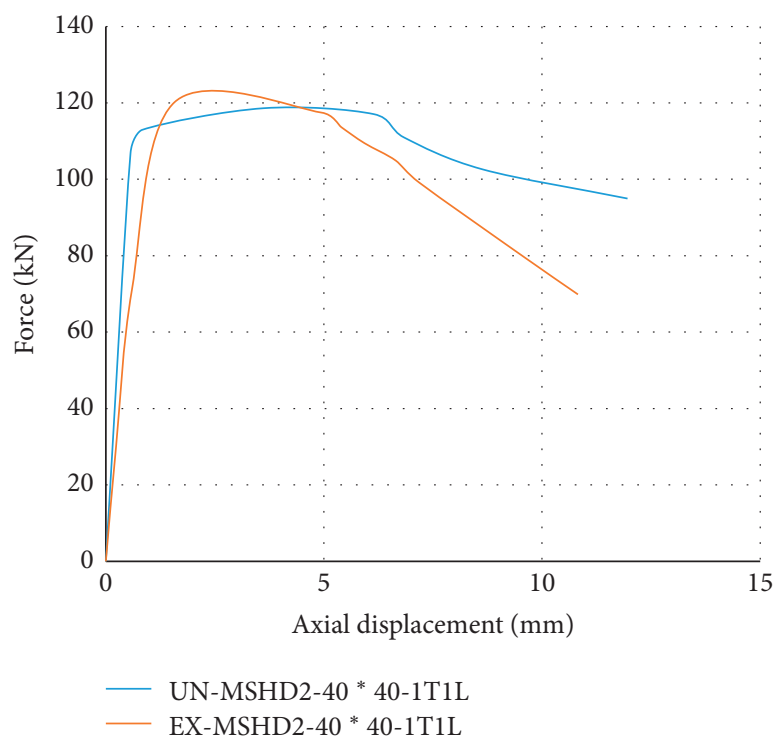

Figure 11: Force-displacement diagram of model and laboratory sample.

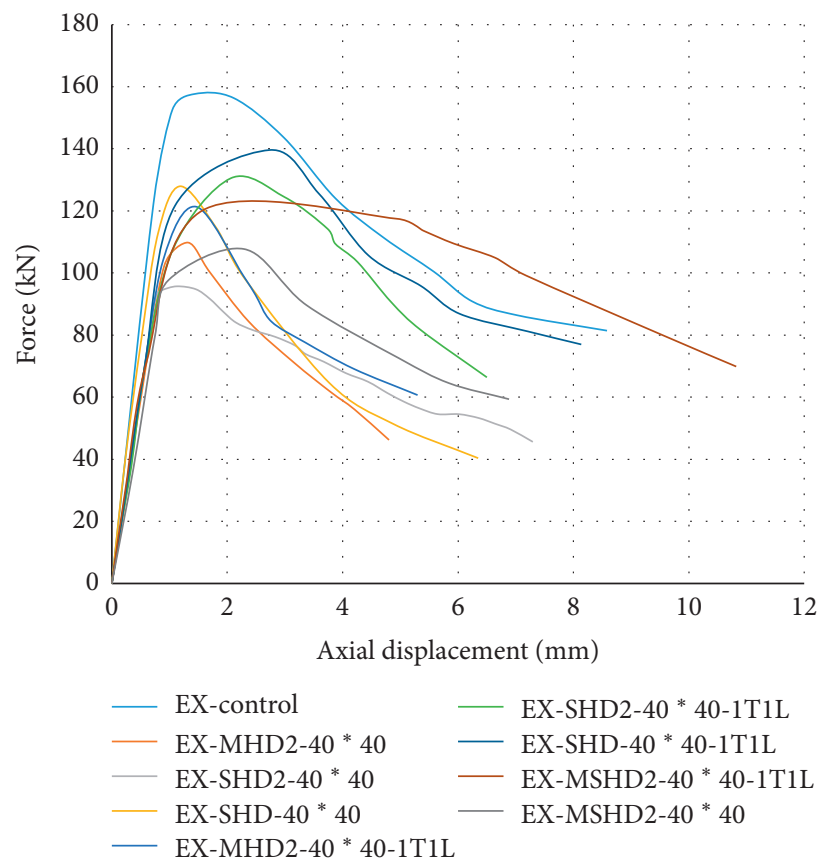

FiguRE 12: Comparison of force-displacement diagram of laboratory samples.

TABle 6: Specifications of laboratory samples and modeling [31].

\begin{tabular}{|c|c|c|c|c|}
\hline Percentage difference & Laboratory bearing capacity $(\mathrm{kN})$ & Carrying capacity modeling $(\mathrm{kN})$ & Sample name & Number \\
\hline 12.03 & 158 & 139 & Control & 1 \\
\hline 12.5 & 112 & 98 & MHD2-40 $\times 40$ & 2 \\
\hline 13.02 & 84 & 95 & SHD2- $40 \times 40$ & 3 \\
\hline 10.21 & 128 & 115 & SHD- $40 \times 40$ & 4 \\
\hline 8.32 & 107 & 98 & MSHD2-40 $\times 40$ & 5 \\
\hline 7.12 & 121 & 112 & MHD2-40× 40-1T1L & 6 \\
\hline 10.25 & 129 & 115 & SHD2-40×40-1T1L & 7 \\
\hline 9.28 & 140 & 127 & SHD- $40 \times 40-1 \mathrm{~T} 1 \mathrm{~L}$ & 8 \\
\hline 5.35 & 125 & 119 & MSHD2-40 × 40-1T1L & 9 \\
\hline
\end{tabular}



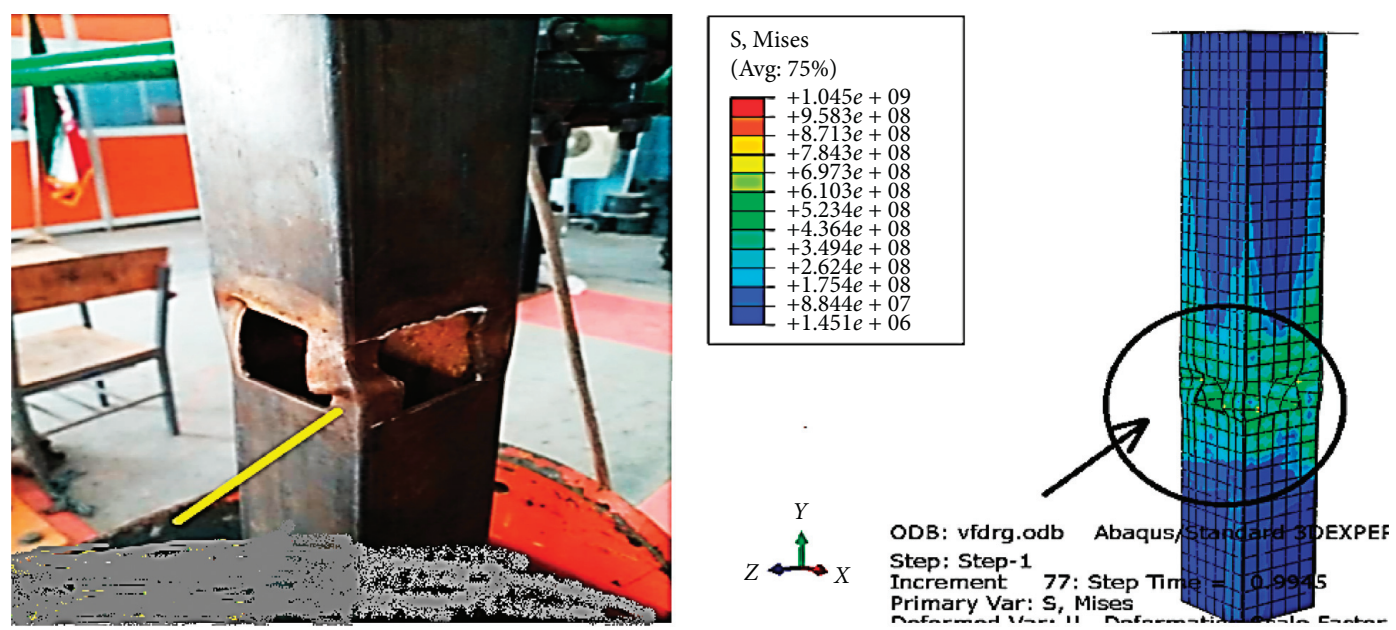

FIgURE 13: Comparison of a defective sample in two adjacent walls of a short steel column.
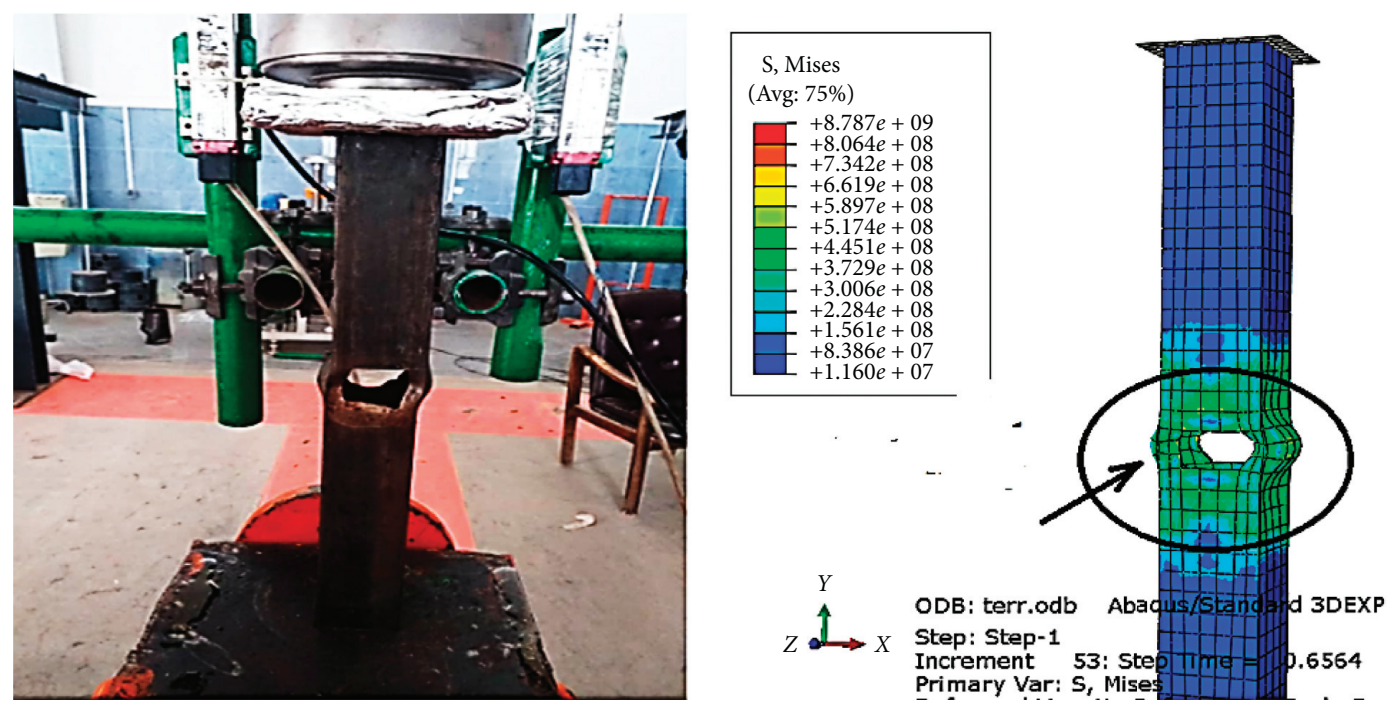

FIgURE 14: Comparison of a sample with defects in two walls in front of a short steel column [33].

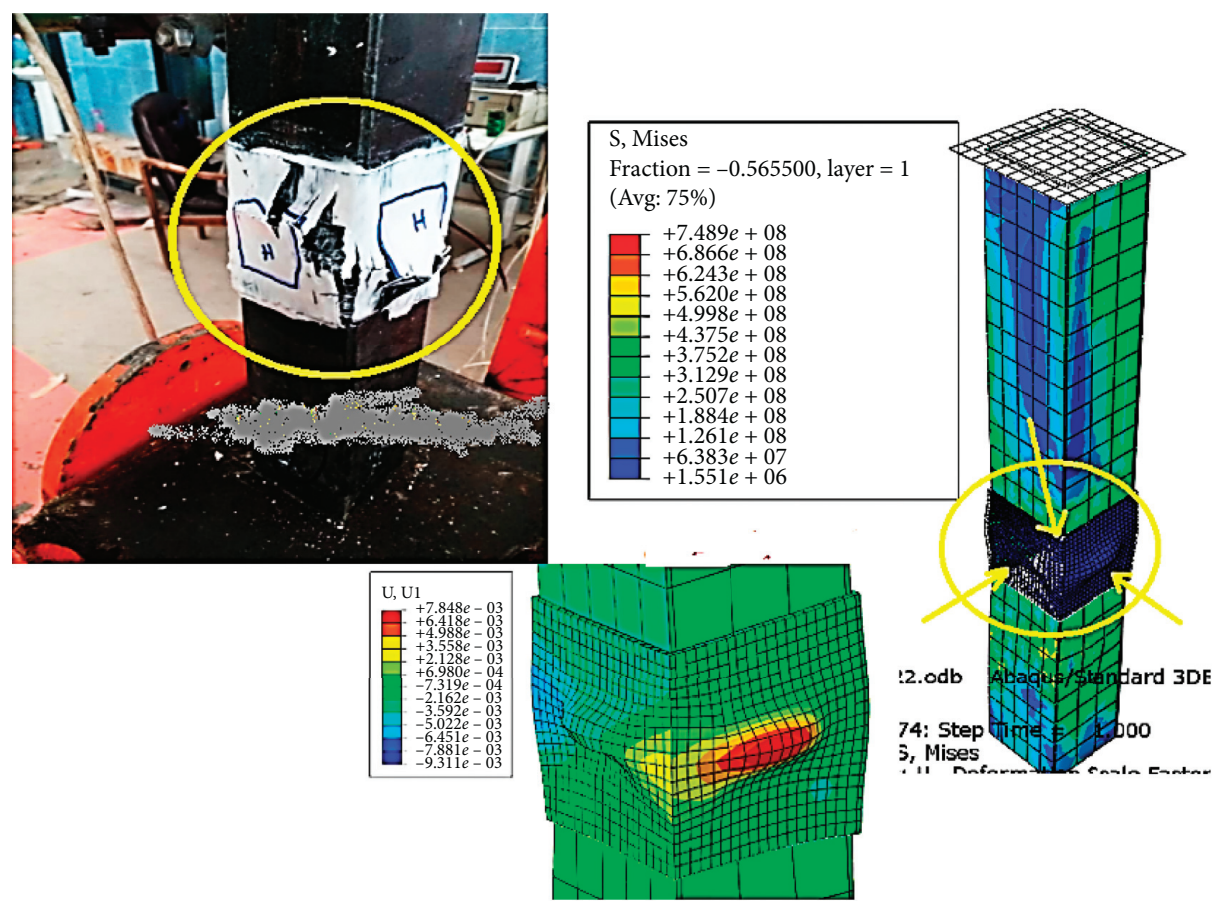

Figure 15: Comparison of the reinforcement of a defective sample in two adjacent walls of a short steel column. 


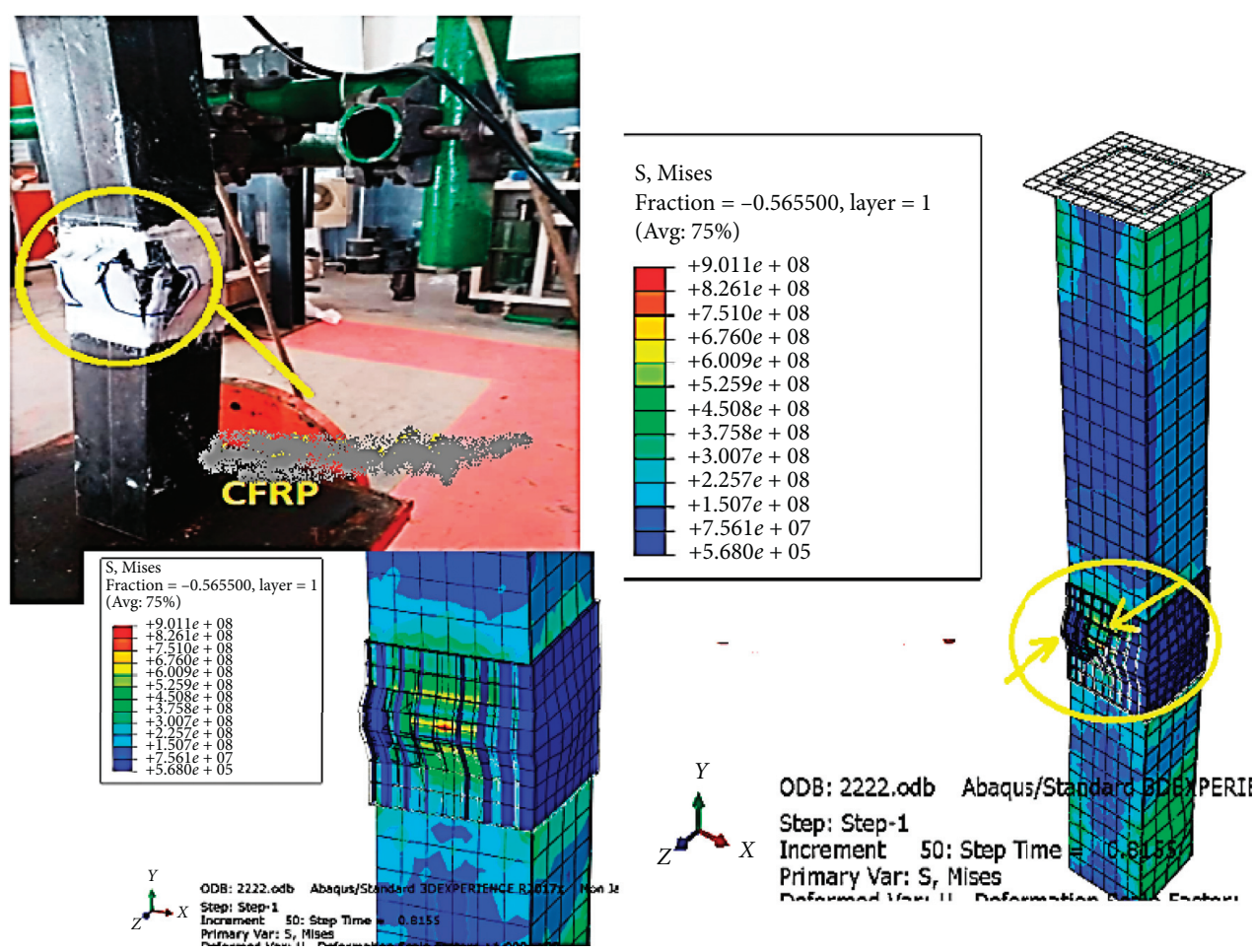

Figure 16: Comparison of the reinforcement of a defective sample on the two sides of a box steel column.

TABLE 7: Bearing capacity of laboratory samples.

\begin{tabular}{lcc}
\hline Carrying capacity $(\mathrm{kN})$ & Sample name & Number \\
\hline 158 & Control & 1 \\
112 & MHD2- $40 \times 40$ & 2 \\
95 & SHD2-40 $\times 40$ & 3 \\
128 & SHD- $40 \times 40$ & 4 \\
107 & MSHD2-40 $\times 40$ & 5 \\
121 & MHD2-40 $\times 40-1 \mathrm{~T} 1 \mathrm{~L}$ & 6 \\
129 & SHD2-40 $\times 40-1 \mathrm{~T} 1 \mathrm{~L}$ & 7 \\
140 & SHD- $40 \times 40-1 \mathrm{~T} 1 \mathrm{~L}$ & 8 \\
125 & MSHD2-40 $\times 40-1 \mathrm{~T} 1 \mathrm{~L}$ & 9 \\
\hline
\end{tabular}

the modeling indicated that FEM will have a high ability to simulate sections under axial load [17].

\section{Conclusion}

Damage to short steel columns increased deformation and rupture in the defect area during axial loading. Increasing the longitudinal dimensions of the defect showed that due to the compressive load, the resistance would decrease and the lateral deformations increase. The effect of corrosion (defect) on the two sides was much greater than the other samples and the deformation in this sample occurred significantly. A horizontal defect created on one side of the center of the box steel column reduced the bearing capacity to $128 \mathrm{kN}$. Also, this reduction in bearing capacity with two layers of CFRP up to $140 \mathrm{kN}$ equal to $8.57 \%$ led to compensation. The horizontal defect created on both sides of the steel column reduced the bearing capacity to $95 \mathrm{kN}$, and this reduction in bearing capacity with the two layers of CFRP increased to $129 \mathrm{kN}$. Longitudinal and transverse dimensions of the corrosion site in box steel columns have reduced the stiffness of the axial member. The use of two layers of CFRP sheet strengthened the metal column damaged by corrosion due to axial load. The stress distribution in all software models, in the place of force application and in the place of failure, was consistent with laboratory samples. The results of software and laboratory analysis were well matched and different from each other. Among the defects created in the reinforced sample, the highest resistance is related to sample No. 8 of Table 7 , with a length and width of the defect of $4 \mathrm{~mm}$, which increased the bearing capacity to $140 \mathrm{kN}$. The use of CFRP carbon fibers to increase the stiffness of the steel column has controlled local buckling and reduced rupture in the defective area. 


\section{Data Availability}

The data used to support the findings of this study are available from the corresponding author upon request.

\section{Conflicts of Interest}

The authors declare that there are no conflicts of interest regarding the publication of this manuscript.

\section{References}

[1] S. M. S. Kolbadi, H. Davoodian, and S. M. S. Kolbadi, "Evaluation of nonlinear behavior of reinforced concrete frames by explosive dynamic loading using finite element method," Civil Engineering Journal, vol. 3, no. 12, pp. 1-10, 2017.

[2] G. Minafò, "A practical approach for the strength evaluation of RC columns reinforced with RC jackets," Engineering Structures, vol. 85, pp. 162-169, 2005.

[3] M. Seyed, K. Seyed, M. Safi, K. Ayoub, S. M. S. Kolbadi, and M. Mirtaheri, "Explosive performance assessment of buried steel pipeline," Advances in Civil Engineering, vol. 2021, Article ID 6638867, 24 pages, 2021.

[4] K. G. Vandoros and S. E. Dritsos, "Concrete jacket construction detail effectiveness when strengthening RC columns," Construction and Building Materials, vol. 22, no. 3, pp. 264-276, 2008.

[5] T. Kitada, T. Yamaguchi, M. Matsumura et al., "New technologies of steel bridges in Japan," Journal of Constructional Steel Research, vol. 58, no. 1, pp. 21-70, 2002.

[6] K. A. Harries, A. J. Peck, and E. J. Abraham, "Enhancing stability of structural steel sections using FRP," Thin-Walled Structures, vol. 47, no. 10, pp. 1092-1101, 2009.

[7] K. A. Harries, A. Peck, and E. J. Abraham, "FRP-stabilised steel compression members," in Proeedings of the Fourth International Conference on FRP Composites in Civil Engineering, Zurich, Switzerland, July 2008.

[8] M. R. Bambach and M. Elchalakani, "Plastic mechanism analysis of steel SHS strengthened with CFRP under large axial deformation," Thin-Walled Structures, vol. 45, no. 2, pp. 159-170, 2007.

[9] M. Bambach, H. H. Jama, and M. Elchalakani, "Static and dynamic axial crushing of spot-welded thin-walled composite steel-CFRP square tubes," International Journal of Impact Engineering, vol. 36, no. 9, pp. 1083-1094, 2010.

[10] J. Haedir and X.-L. Zhao, "Design of short CFRP-reinforced steel tubular columns," Journal of Constructional Steel Research, vol. 67, no. 3, pp. 497-509, 2011.

[11] S. Kalavagunta, S. Naganathan, and K. N. Bin Mustapha, "Proposal for design rules of axially loaded CFRP strengthened cold formed lipped channel steel sections," Thin-Walled Structures, vol. 72, pp. 14-19, 2013.

[12] M. A. Hadianfard, S. Malekpour, and M. Momeni, "Reliability analysis of $\mathrm{H}$ section steel columns under blast loading," Structural Safety, vol. 75, pp. 45-56, 2018.

[13] M. Liu and M. Dawood, "Reliability analysis of debonding in steel beams strengthened with externally bonded CFRP composites," Journal of Composites for Construction, vol. 23, no. 1, pp. 65-70, 2019.

[14] J. G. Teng, T. Yu, and D. Fernando, "Strengthening of steel structures with fiber-reinforced polymer composites," Journal of Constructional Steel Research, vol. 78, pp. 131-143, 2012.
[15] J. G. Teng and Y. M. Hu, "Enhancement of seismic resistance of steel tubular columns by FRP jacketing," in Proceedings of the 3rd International Conference on Composites in Construction, pp. 11-13, Lyon, France, July 2005.

[16] A. Tanabandeh and P. Gardoni, "Probabilistic capacity models and fragility estimates for RC columns retrofitted with FRP composites," Engineering Structures, vol. 74, pp. 13-22, 2014.

[17] M. R. Bambach and M. Elchalakani, "Plastic mechanism analysis of steel SHS strengthened with CFRP under large axial deformation," Thin-Walled Structures, vol. 45, no. 2, pp. 159-170, 2007.

[18] D. Zhang, Q. Wang, and J. Dong, "Simulation study on CFRP strengthened reinforced concrete beam under four-point bending," Computers and Concrete, vol. 17, no. 3, pp. 407-421, 2016.

[19] H. Yang and A. Wang, "Dynamic stability analysis of pipeline based on reliability using surrogate model," Journal of Marine Engineering \& Technology, vol. 12, no. 2, pp. 75-84, 2014.

[20] S. M. Seyed Kolbadi, H. Piri, K. Ali, S. Mahdi Seyed-Kolbadi, and M. Mirtaheri, "Nonlinear seismic performance evaluation of flexural slotted connection using endurance time method," Shock and Vibration, vol. 2020, Article ID 8842230, 15 pages, 2020.

[21] K. Ha, "Innovative blade trailing edge flap design concept using flexible torsion bar and worm drive," Hightech and Innovative Journal, vol. 1, no. 3, pp. 12-20, 2020.

[22] A. P. Pinheiro, "Architectural rehabilitation and sustainability of green buildings in historic reservation," Hightech and Innovative Journal, vol. 1, no. 4, pp. 26-44, 2020.

[23] N. Kabashi, B. Avdyli, E. Krasniqi, and A. Këpuska, "Comparative approach to flexural behavior of reinforced beams with GFRP," CFRP and Steel Bars, civil engineering Journal, vol. 6, no. 1, pp. 32-50, 2020.

[24] D. He, J. Dong, Q. Wang, and X. Chen, "Mechanical behaviour of recycled concrete filled steel tube columns strengthened by CFRP," in Proceedings of the Paper presented at the 2nd International Conference on Multimedia Technology, Hangzhou, China, March 2001.

[25] P. Feng, Y. Zhang, Y. Bai, and L. Ye, "Strengthening of steel members in compression by mortar-filled FRP tubes," ThinWalled Structures, vol. 64, pp. 1-12, 2013.

[26] T. Georgia, P. Vassilis, and K. Andreas, "Flexural behaviour of reinforced concrete jacketed columns under reversed cyclic loading," Engineering Structures, vol. 50, pp. 432-443, 2014.

[27] L. H. Han, G. H. Yao, and X. L. Zhao, "Tests and calculations for hollow structural steel (HSS) stub columns filled with selfconsolidating concrete (SCC)," Journal of Constructional Steel Research, vol. 61, pp. 1241-1269, 2015.

[28] H. Karagah, C. Shi, M. Dawood, and A. Belarbi, "Experimental investigation of short steel columns with localized corrosion," Thin-Walled Structures, vol. 87, pp. 191-199, 2015.

[29] N. Metropolis and S. Ulam, "The Monte Carlo method," Journal of the American Statistical Association, vol. 44, no. 247, pp. 335-341, 1949.

[30] A. S. Nowak and K. R. Collin, Reliability of Structures, McGraw-Hill, New York, NY, USA, 2000.

[31] M. R. Ghaemdoust, K. Narmashiri, and O. Yousefi, "Structural behaviors of deficient steel SHS short columns strengthened using CFRP," Construction and Building Materials, vol. 126, pp. 1002-1011, 2016.

[32] J. F. Dong, Q. Y. Wang, and Z. W. Guan, "Structural behaviour of recycled aggregate concrete filled steel tube 
columns strengthened by CFRP," Engineering Structures, vol. 48, pp. 532-542, 2013.

[33] G. G. Prabhu and M. C. Sundarraja, "Behaviour of concrete filled steel tubular (CFST) short columns externally reinforced using CFRP strips composite," Construction and Building Materials, vol. 47, pp. 1362-1371, 2013. 